\title{
Revision of some species of the genus Cryptosporidium (Tyzzer, 1907) (Eucoccidiorida, cryptosporidiidae) in cattle in Iraq
}

\author{
Zainab A. Makawi, Hind D Hadi ${ }^{1}$ and Azhar Ali ${ }^{2}$ \\ ${ }^{1}$ Iraq Natural History Research Center and Museum, University of Baghdad, Baghdad, Iraq. \\ ${ }^{2}$ College of Veterinary Medicine, University of Baghdad, Baghdad, Iraq.
}

GSC Biological and Pharmaceutical Sciences, 2021, 14(01), 116-120

Publication history: Received on 02 January 2021; revised on 10 January 2021; accepted on 12 January 2021

Article DOI: https://doi.org/10.30574/gscbps.2021.14.1.0003

\begin{abstract}
Cryptosporidium is a protozoan parasite of medical and veterinary significance that causes gastroenteritis in a number of vertebrate hosts. Several studies have recorded different degrees of pathogenicity and virulence among Cryptosporidium species and isolates of the same species as well as evidence of variation in host susceptibility to infection. Nevertheless, important progress has been made in determining Cryptosporidium's putative virulence factors. Since the publication of $C$ parvum and $C$. Hominis this development has been accelerated genomes, identified by a range of immunological and molecular techniques with the characterization of over 25 putative virulence factors, which are proposed to be involved in aspects of host-pathogen interactions from adhesion and locomotion to invasion and proliferation. There has also been improvement in the contribution of host variables correlated with differences in both the severity and risk of infection. In view of our current understanding of microbial virulence, we present a summary of the current state of information on Cryptosporidium infectivity, pathogenesis, and transmissibility here.
\end{abstract}

Keywords: Cryptosporidium; Cattle; Breeds; Virulence; Tyzzer

\section{Introduction}

The disease caused by a protozoan parasite of the genus Cryptosporidium, which was discovered in the gastric glands of mice by Edward Ernst Tyzzer in 1910, is Cryptosporidiosis. Tyzzer found that within the oocysts, this parasite did not produce sporocysts and it sporulates while still attached to the host wall. For this reason, from the Greek kruptos meaning 'secret', Tyzzer called the genus Cryptosporidium, and the parasite that he identified in the gastric glands, Cryptosporidium muris.

Three years later, Tyzzer described another Cryptosporidium species that was not contagious but only in the small intestine in the gastric glands of mice [1]. Compared $C$, muris oocysts $(6-8 \mu \mathrm{m})$ with second species developed oocysts that were smaller in size $(4-5 \mu \mathrm{m})$. This species was called Cryptosporidium parvum by Tyzzer (parvum comes from the Latin for little). Originally, it was assumed that there were only two distinct Cryptosporidium species, but there are now more than 27 species described and several more genotypes [2].

In 1971, Cryptosporidium was first identified with diarrhoea in calves [3] and has since been recognized as one of the world's leading causes of neonatal enteritis in calves. $[4 ; 5 ; 6]$.

\footnotetext{
* Corresponding author: Zainab A

Iraq Natural History Research Center and Museum, University of Baghdad, Baghdad Iraq. 


\section{Classification of Cryptosporidium}

\subsection{Kingdom: Protozoa}

Phylum: Apicomplexa

Classification: Sporozoasida

Subclass: Coccidiasina

Order: Eucoccidiida

Suborder: Eimeriina

Family: Cryptosporidiidae

Genus: Cryptosporidium [7]

\section{Species of Cryptosporidium in cattle}

Four Cryptosporidium species are commonly found in cattle; C. Parvum, C. Bovis, C.Ryanae and C. andersoni . There are several records that other species are also found C.hominis were confirmed in a 3-day-old calf and a 6-year-old cow from Scotland [8], C. suis in a calf [9] and C. Felis in a cattle [10]. but such records are rare.

\section{Morphology and life cycle}

The infectious stage of the parasite is sporulated oocysts. They are 4-6 $\mu \mathrm{m}$ with a thick wall containing four sporozoites in a spherical to ovoid shape [11]. Cryptosporidium is a monoxenic (life cycle completed inside a single host) organism that resides in thick walled oocysts in the environment. Many environmental conditions, such as high and low temperatures, are very immune to these oocysts. [12] . But they can be inactivated by desiccation, In cold, moist climates, Cryptosporidium oocysts live well and can remain infectious for several months [13]. The host ingests infective Cryptosporidium oocysts and excystation occurs when caused by the conditions in the gastrointestinal tract (low $\mathrm{pH}$, body temperature). [14]. And they release four sporozoites. At the ileocaecal junction, the sporozoites bind to the host epithelial cells, which are then invaded and swallowed by the cells that form a parasitophorous vacuole. Within a parasitophorous vacuole, several other protozoan parasites also exist, but Cryptosporidium also has a special structure known as the feeder organelle, which separates the cytoplasm cell and parasite. The sporozoite itself becomes more spherical in shape after the feeder organelle's development and forms a trophozoite. The parasite starts to replicate asexually and evolves into a meront type I or a meront type II. Within the Type I meront, merozoites are created, each Type I meront releases 6-8 merozoites that can reinfect the host immediately by invading neighboring cells and starting asexual reproduction again, or developing into a Type II meront. It release four merozoites which initiate the sexual reproductive cycle. Host cells are invaded by the released merozoites and differentiate into macrogamonts or microgamonts. Microgamonts grow multi-nuclei and release free microgametes that penetrate and fertilize the macrogamete, forming a zygote. Meiosis occurs and, as the oocyst grows and is released from the lumen, the zygote differentiates into four sporozoites. The sporozoites may be released from thin-walled oocysts directly into the lumen and reinfect the host or thick-walled oocysts that are shed in faeces and remain instantly contagious for other hosts. [15].

\section{Diagnosis of Cryptosporidium spp}

The diagnosis of Cryptosporidium oocysts, a range of laboratory methods are available: staining with fluorescent or acid quick stains, enzyme immunoassays, immune chromatographic methods and molecular methods [16]. A research by Chalmers [17] shows that microscopy of immunofluorescence is more susceptible than enzyme immunoassay and graphic lateral flow of immune chromate, As well as being more susceptible to auramine phenol staining and modified Ziehl-Neelsen than the UK norm methods. The overall favored approach for the detection of Cryptosporidium spp. is immunofluorescence microscopy. In Europe and in the USA [18]. In the last decade, molecular methods have been developed extensively in research laboratories, yielding polymerase chain reaction (PCR) methods of high sensitivity and specificity for detection of Cryptosporidium spp. [19]. 


\section{Review in the previous studies Distribution of Cryptosporidium species in different cattle breeds}

Cryptosporidium oocysts are transmitted through the faecal-oral route between hosts, either directly through contact with the faeces of infected animals or indirectly via contamination of the environment or by ingestion of contaminated food or water [20]. Among cattle, shortly after birth, calves are susceptible to infection and remain so for several months. Infection in dairy calves is found most commonly between the ages of 8 and 15 days, infection in beef calves most often occurs between 1 and 2 months of age [21;22]. Potential causes of waterborne pollution should be considered for livestock living near to rivers, as surface run-off transports Cryptosporidium oocysts to water bodies in soils. Cryptosporidium oocysts have been recovered from untreated surface water (rivers, streams and reservoirs), untreated and treated wastewater, filtered swimming pool water and, most notably, from sources of treated drinking water. [23]. Another risk factor found to raise the likelihood of calves shedding oocysts is repeated changes in bedding as staff and equipment used to remove the bedding can potentially become a vector for spreading the infection. [24].

The overall prevalence of Cryptosporidium infection was 35.44\%, with C. parvum was the dominated species before six month age, and $C$. andersoni in calves older than that [25]. Prevalence for Cryptosporidium was $1.0 \%$ in dairy cattle in Hebei and Tianjin, China [26]. Prevalence of Cryptosporidium infection in cattle from South Western Nigeria, prevalence of infection was $23.4 \%$ (95/406), with an infection rate of $27.4 \%, 28.1 \%$ and $19.9 \%$ in cattle less than 6 months, $7-12$ months and over 12 months respectively [27]. Prevalence, risk factors and molecular characterization of infection with Cryptosporidium in Addis Ababa and surrounding cattle, Ethiopia, C. parvum and C. Andersoni in $27 \%$ and $73 \%$ of pathogens, respectively, $C$. Parvum occurs exclusively in calves younger than 2 months of age and $C$. andersoni in heifers and in adult cattle only [28]. Of the 37 beef cows and 115 calves examined, four (10.8\%) and 14 (12.2\%), respectively, were positive for Cryptosporidium [29]. Of the 37 beef cows and 115 calves analyzed, four (10.8 \%) and 14 (12.2\%) were positive for Cryptosporidium. In different regions of China, the prevalence of Cryptosporidium infection in cattle, the total infection rate was $11.9 \%$, and the rate of infection differed significantly for different regions. [30]. The overall prevalence rate for Cryptosporidium spp. In Egypt, cattle accounted for $10.2 \%$ [31]. Prevalence of Cryptosporidium spp. and molecular characterization A total of 387 (18.82\%) positive samples were detected in dairy cattle from farms in China and further analyzed by polymerase chain reaction (PCR) using primers designed to amplify DNA fragments from a small subunit of ribosomal RNA. [32]. prevalence of $C$. parvum subtype in bovine calves was $18.31 \%$ cattle of north India [33]. Prevalence was significantly higher $(\mathrm{P}<0.001)$ among cattle from the forest-savannah transition zone (50.6\%) compared to the coastal savannah zone (18.9\%) Prevalence of Cryptosporidium oocysts in cattle from Southern Ghana [34].

\section{Pathogenesis and Clinical sings}

There is a limited understanding of the pathogenic mechanisms by which Cryptosporidium induces diarrhea, malabsorption and wasting. The initial host-parasite experiences of attachment and invasion are essential primary events in pathogenesis, whatever these mechanisms may be. It has defined the ultrastructural characteristics of attachment and invasion and various factors influencing attachment. Specific parasites and host molecules involved in these processes, however, are little understood [35]. To understand the pathogenic mechanisms employed by this parasite, knowledge of certain molecules is essential. Complex processes that include multiple parasite ligands and host receptors are the initial host-parasite interactions of attachment, invasion and parasitophorous vacuole formation. In apicomplexans, such as Toxoplasma, Plasmodium and Eimeria, these interactions were best studied. Specialized secretory organelles possess intrusive "zoite" phases of apicomplexans (rhoptries, micronemes and dense granules) Known collectively as the apical complex. These organelles secrete and successively exocytose proteins during initial host-parasite interactions, which promote attachment, invasion and parasitophorous vacuole formation. Many micronemal proteins have "modules" of adhesive that are retained among apicomplex parasites, while others express distinctive domains [36]. Medical symptoms of $C$ parvum infections are characterized by anorexia, depression, weight loss, diarrhea, vomiting, increased morbidity and probably death from dehydration. [37; 38].

\section{Conclusion}

Cryptosporidiosis is a problem in ruminants that are neonatal. During the first weeks of the life of calves, Cryptosporidium parvum is the most common intestinal pathogen and is an important factor in the etiology of diarrheal syndrome caused by the parasite alone, but losses are more pronounced when concurrent intestinal pathogens are present. Cryptosporidium causes economic losses, including delayed growth and mortality, and a variety of costs that are difficult to quantify as a result of diarrhea-related treatments. The study's advantage is a database on which researchers rely to analyze the types of Cryptosporidium that infect cows, And to raise awareness of the implementation of measures of hygiene and good management that are deemed more effective in the fight against this disease. 


\section{Compliance with ethical standards}

\section{Acknowledgments}

My thanks to my teachers and colleagues in the scientific process.

\section{Disclosure of conflict of interest}

There was no conflict of interest in this study.

\section{References}

[1] Tyzzer EE. An Extracellular coccidium , cryptosporidium muris of the gastric glands of the common mouse . Journal of medical research. 1910; 23: 487-509.

[2] Chalmers RM, Katzer F. Looking for Cryptosporidium: the application of advances in detection and diagnosis. Trends in Parasitology. 2013; 29: 237- 251.

[3] Panciera RJ, Thomassen RW, Garner FM. Cryptosporidial Infection in a Calf. Vet Pathol. 1971; 8: 479-484.

[4] De Graaf DC, Vanopdenbosch E, Ortega-Mora LM, Abbasi H, Peeters JE. A review of the importance of cryptosporidiosis in farm animals. International Journal for Parasitology. 1999; 29: 1269-1287.

[5] Fayer R, Gasbarre L, Pasquali P, Canals A, Almeria S, Zarlenga D. Cryptosporidium parvum infection in bovine neonates: dynamic clinical, parasitic and immunologic patterns. Int J Parasitol. 1998; 28: 49-56.

[6] Thompson RC, Olson ME, Zhu G, Enomoto S, Abrahamsen MS, Hijjawi NS. Cryptosporidium and cryptosporidiosis. Adv. Parasitol. 2005; 59: 77- 158.

[7] Levine ND. Phylum II Apicomplexa Levine, 1970. In: An Illustrated Guide to the Protozoa, Lee, J.J., S.H. Humter and E.C. Bovee (Eds.). Allen Press, Lawrenc. 1985; 322-374.

[8] Smith HV, Nichols RA, Mallon M, MacLeod A, Tait A, Reilly WJ, Browning LM, Gray D, Reid SW, Wastling JM. Natural Cryptosporidium hominis infections in Scottish cattle. Veterinary Record. 2005; 156: 710-711.

[9] Fayer R, Santin M, Trout JM, Greiner E. Prevalence of species and genotypes of Cryptosporidium found in 1-2year-old dairy cattle in the eastern United States. Veterinary Parasitology. 2006; 135: 105-112.

[10] Bornay-Llinares FJ, da Silva AJ, Moura IN, Myjak P, Pietkiewicz H, Kruminis-Lozowska W, Graczyk TK, Pieniazek, NJ. Identification of Cryptosporidium felis in a cow by morphologic and molecular methods. Appl. Environ. Microbiol. 1999; 65: 1455-1458.

[11] Fayer R, Xiao L. Cryptosporidium and Cryptosporidiosis. 2nd edition. Boca Raton, London, New York, CRC Press. 2008; 1 - 450.

[12] Fujino T, Matsui T, Kobayashi F, Haruki K, Yoshino Y, Kajima J, Tsuji M. The effect of heating against Cryptosporidium oocysts. J Vet Med Sci. 2002; 64: 199 - 200(2) .

[13] Robertson LJ, Campbell AT, Smith HV. Survival of Cryptosporidium parvum oocysts under various environmental pressures. Appl. Environ. Microbiol. 1992; 58: 3494-3500.

[14] Hijjawi NS, Meloni BP, Ryan UM, Olson ME, Thompson RC. Successful in vitro cultivation of Cryptosporidium andersoni: evidence for the existence of novel extracellular stages in the life cycle and implications for the classification of Cryptosporidium. Int J Parasitol. 2002; 32: 1719-1726.

[15] Pohlenz J, Bemrick WJ, Moon HW, Cheville NF. Bovine cryptosporidiosis: a transmission and scanning electron microscopic study of some stages in the life cycle and of the host-parasite relationship. Vet. Pathol. 15, 417-427.

[16] Caccio SM, Chalmers RM. Human cryptosporidiosis in Europe. Clinical Microbiology and Infection. 2016; 22(6): 471-480.

[17] Chalmers RM, Campbell BM, Crouch N, Charlett A, Davies AP. Comparison of diagnostic sensitivity and specificity of seven Cryptosporidium assays used in the UK. Journal of Medical Microbiology. 2011; 60(11): 1598-1604.

[18] Checkley W, White AC, Jaganath D, Arrowood MJ, Chalmers RM, Chen X-M, Houpt ER. A review of the global burden, novel diagnostics, therapeutics, and vaccine targets for Cryptosporidium. The Lancet Infectious Diseases. 2015; 15(1): 85-94. 
[19] Hadfield SJ, Robinson G, Elwin K, Chalmers RM. Detection and differentiation of Cryptosporidium spp. in human clinical samples by use of real-time PCR. Journal of Clinical Microbiology. 2011; 49(3): 918-924.

[20] Gait R, Soutar R, Hanson M, Fraser C, Chalmers R. Outbreak of cryptosporidiosis among veterinary students. The Veterinary Record. 2008; 162: 843.

[21] Garber LP, MD Salman, HS Hurd, T Keefe, JL Schlater, Potential risk factors forCryptosporidium infection in dairy calves. J. Am. Vet. Med. Assoc. 1994; 205: 86-91.

[22] Ramirez NE, LA Ward, SA Sreevatsan. A review of the biology and epidemiology ofcryptosporidiosis in humans and animals. Microb. Infect. 2004; 6: 773-785.

[23] Richardson AJ, RA Frankenberg, AC Buck, JB Selkon, JS Colbourne, JW Parsons, RT Mayon-White. An outbreak of waterborne cryptosporidiosis in Swindon andOxfordshire. Epidemiol. Infect. 1991; 107: 485-495.

[24] Sischo WM, ER Atwill, LE Lanyon, J George. Cryptosporidia on dairy farms and therole these farms may have in contaminating surface water supplies in the Northeastern UnitedStates. Prev. Vet. Med. 2000; 43: 253-267.

[25] Al-zubaidi MTHS. Prevalence of some Cryptosporidium species in cattle in Baghdad ,Iraq. AL-Qadisiya Journal of Vet.Med.Sci. 2012; 11(2).

[26] Suhui Hua b, Zhenzhen Liua b, Fengbin Yana, Zhenjie Zhanga b, Guiling Zhanga b, Longxian Zhanga b, Fuchun Jiana b, Sumei Zhanga, Changshen Ninga b, Rongjun Wanga b. Zoonotic and host-adapted genotypes of Cryptosporidium spp., Giardia duodenalis and Enterocytozoon bieneusi in dairy cattle in Hebei and Tianjin, China. Veterinary Parasitology. 2017; 248: 68-73.

[27] Ayinmode, Adekunle B, Fagbemi, Benjamin O. Prevalence of Cryptosporidium infection in cattle from South Western Nigeria. Veterinarskiarhiv. 2010; 80(6): 723-731.

[28] Manyazewala A, Stomeo Francescab, Mahendra Pala, Mamo Gezahegna, Mulatu Tesfayec, Muthui Lucyb, Wegayehu Teklud, Tilahun Getachewe. Prevalence, risk factors and molecular characterization of Cryptosporidium infection in cattle in Addis Ababa and its environs, Ethiopia. Veterinary Parasitology: Regional Studies and Reports. 2018; 13: 79-84.

[29] Holsback L, Heloísa Eid Lima, Odilon Vidotto, Marcelo Alves da Silva, Thaís Helena Constantino Patelli, Felippe Danyel Cardoso Martins, Mércia de Seixas. Cryptosporidium occurrence in ruminants from the North Pioneer mesoregion of Paraná, Brazil. Braz. J. Vet. Parasitol., Jaboticabal. 2018; 27(2): 248-253.

[30] Gong c, Xue-Feng Cao a, Lei Denga, Wei Li a, Xiang-Ming Huang, Jing-Chao Lan, Qi-Cheng Xiao, Zhi-Jun Zhong, Fan Feng, Yue Zhang, Wen-Bo Wang, Ping Guo, Kong-Ju Wu, Guang-Neng Peng. Epidemiology of Cryptosporidium infection in cattle in China: a review. Parasite published by EDP Sciences. 2017; $24: 1$.

[31] Ibrahim MA, AE Abdel-Ghany, G K Abdel-Latef, SA Abdel-Aziz, SM Aboelhadid. Epidemiology and public health significance of Cryptosporidium isolated from cattle, buffaloes, and humans in Egypt. Parasitol Res. 2016; 115: 2439-2448.

[32] Chen Fu, Huang K. Prevalence and molecular characterization of Cryptosporidium spp. In dairy cattle from farms in China, J. Vet. Sci. 2011; 13(1): 15-22.

[33] Maurya PS, Rajat Garg, Banerjee PS, Saroj K, Rakesh RL, Kundu K, RAM H, Raina OK. Genotyping of Cryptosporidium species reveals prevalence of zoonotic C. parvum subtype in bovine calves of north India. Indian Journal of Animal Sciences. 2013; 83(10): 1018-1023.

[34] Squire Sylvia A, Julius Beyuo, Hamphery Amafu-Dey. Prevalence of Cryptosporidium oocysts in cattle from Southern Ghana. VETERINARSKI ARHIV. 2013; 83(5): 497-507.

[35] Theodos CM. Innate and cell-mediated immune responses to Cryptosporidium parvum. Adv. Parasitol. 1998; 40: 87-119.

[36] Ward H, Cevallos AM. Cryptosporidium: molecular basis of host-parasite interaction. Adv Parasitol. 1998; 40: 151-185.

[37] Navarre CB, Pugh DG. Diseases of the Gastrointestinal System. In: Pugh, D.G. (Eds): Sheep and Goat Medicine. Saunders, An Imprint of Elsevier. Philadelphia, Pennsylvania. 2002.

[38] Radostits OM, Gay CC, Hinchcliff KW, Constable PD. Diseases associated with protozoa. 10th Edn. In: Veterinary Medicine: A Textbook of Diseases of cattle, horses, sheep, pigs, and goats. Saunders Elsevier. 2008; 1483-1540. 